\title{
A PRECESSÃO DOS EQUINÓCIOS E A MATEMÁTICA DA CRIAÇÃO
}

MUNIZ, Gustavo Ferreira ${ }^{1}$

MUNIZ, Gustavo Ferreira. A precessão dos equinócios e a matemática da

criação. Revista Científica Multidisciplinar Núcleo do Conhecimento. Ano 03, Ed. 01 , Vol. 03, pp. 15-30, Janeiro de 2018. ISSN: 2448-0959, Link de acesso:

https://www.nucleodoconhecimento.com.br/matematica/matematica-da-criacao, DOI: 10.32749/nucleodoconhecimento.com.br/matematica/matematica-da-criacao

\section{RESUMO}

Este artigo traz informações contidas no livro: Órion a conexão entre o céu e a Terra, onde um alinhamento na Amazônia boliviana conecta as principais estruturas megalíticas encontradas pelo mundo, suas referências criam um raciocínio matemático inédito, onde em seus resultados, correspondências numéricas pertinentes às dimensões da Terra, da Lua e do Sol, são expostas por intermédio dos principais números da Matemática, juntamente com dados relativos a um dos eventos astronômicos mais importantes desse século, ocorrido no ano de 2.012, conhecido como a precessão dos equinócios, essas relações nos trazem indicações de que uma civilização hidráulica sofisticada tenha prosperado em uma vasta área da Amazônia em um passado remoto.

Palavras-chaves: alinhamento, Matemática, precessão dos equinócios.

\section{INTRODUÇÃO}

A precessão dos equinócios é um movimento cônico de longa duração catalogado por uma das primeiras civilizações que temos conhecimento: os sumérios, também

\footnotetext{
${ }^{1}$ Músico, especializado em Tecnologia, linux, banco de bados, redes, ex-gerente de sistemas da FAPDF (Fundação de Apoio à Pesquisa do Distrito Federal), Servidor Público.
}

$\mathrm{RC}: 13257$

Disponível em: https://www.nucleodoconhecimento.com.br/matematica/matematica- 
chamado de o Grande Ano ou Ano Platônico, este ciclo possui uma duração de 25.920 anos, é subdividido em 12 eras, cada uma com 2.160 anos e a cada 72 anos, percorre $1^{\circ}$ grau em seu eixo precessional. Esse ciclo findou-se em dezembro de 2.012, (GADALLA, MOUSTAFA) onde ficou muito conhecido por conta do calendário maia, (Fenômeno 2012) porém, alguns segmentos como a indústria do entretenimento aproveitando-se dessa situação, relacionou-o unicamente a um período de cataclismos, como no filme lançado em 2009 com o título: 2012. (2012 Filme)

Outras civilizações como as egípcias, maias e astecas, localizadas em diferentes épocas e continentes, conheciam esse ciclo e ao mesmo tempo sua relevância, construíram suas obras arquitetônicas complexas alinhadas para sinalizarem com exatidão esse grande evento astronômico, que a partir de agora, com informações contidas no alinhamento encontrado na Bolívia, nos trarão novas perspectivas sobre o que ele de fato, estaria revelando.

Em Yacuma, província do Departamento de Benina Amazônia boliviana, há uma localização encontrada por meio do aplicativo Google Earth, onde ilhas florestas conectadas por extensos canais a lagoas artificiais retangulares, espalhadas em uma grande área, provavelmente feitas pela ação antrópica em um período remoto, estão numa disposição em que acabam revelando um diagrama no solo onde é possível identificar por intermédio de uma visão aérea, referências que nos conduzem à constelação de Órion, evidenciando que está localização é o centro de um alinhamento simétrico contendo 12 segmentações, conectando as principais estruturas megalíticas encontradas pelo Globo, essas entre outras situações, expõem traços de que uma antiga civilização hidráulica tenha pertencido a essa região no passado e sabemos muito pouco ao seu respeito até o momento.

RC: 13257

Disponível em: https://www.nucleodoconhecimento.com.br/matematica/matematica- 


\section{ALINHAMENTO PRINCIPAL, YACUNA - BENI, BOLÍVIA}

Figura 1: Alinhamento principal, Yacuna - Beni, Bolívia.

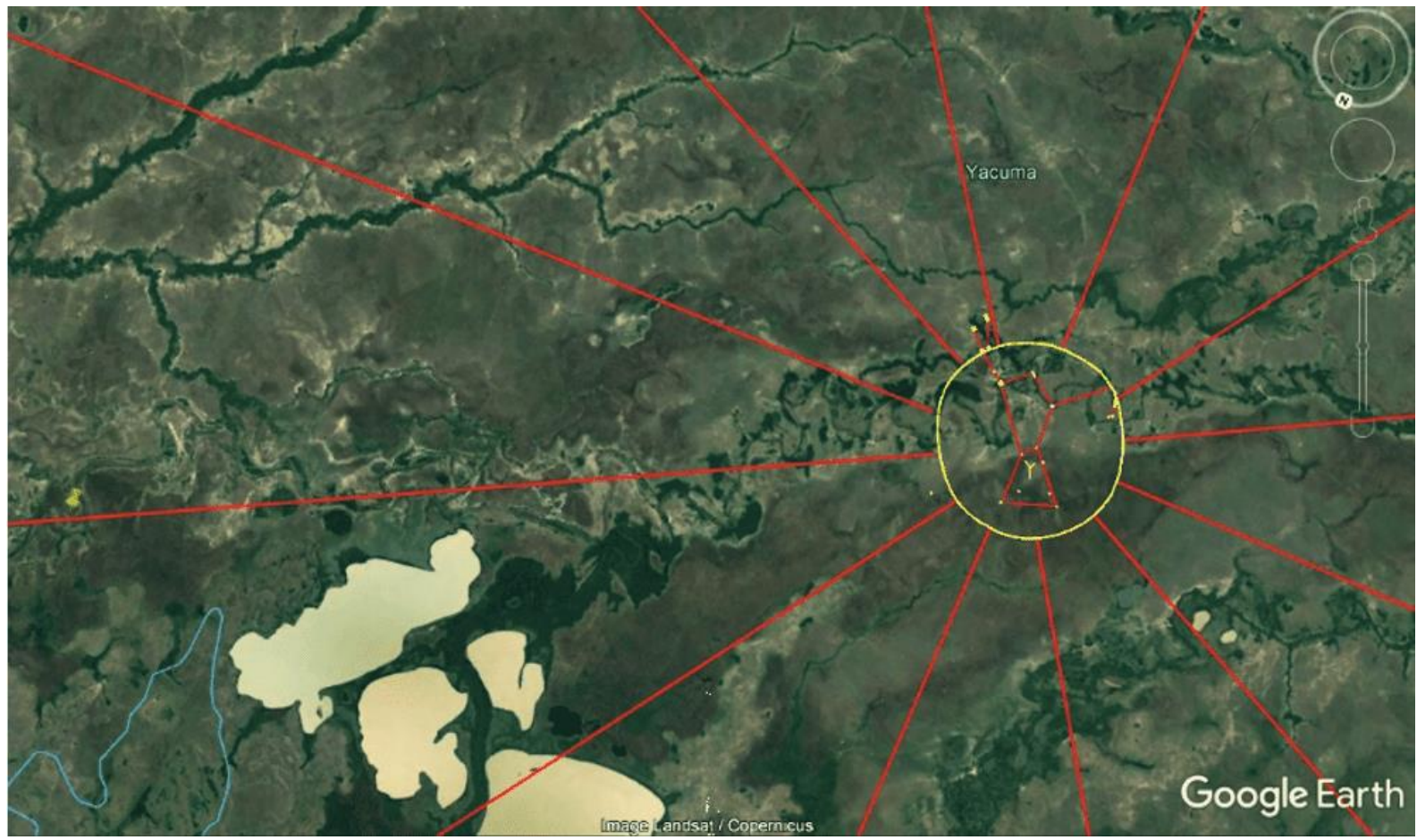

Imagem satelital - Google Earth.

RC: 13257

Disponível em: https://www.nucleodoconhecimento.com.br/matematica/matematicada-criacao 


\section{ILHA FLORESTA, AMAZÔNIA BOLIVIANA}

Figura 2: Ilha Floresta, Amazônia boliviana.

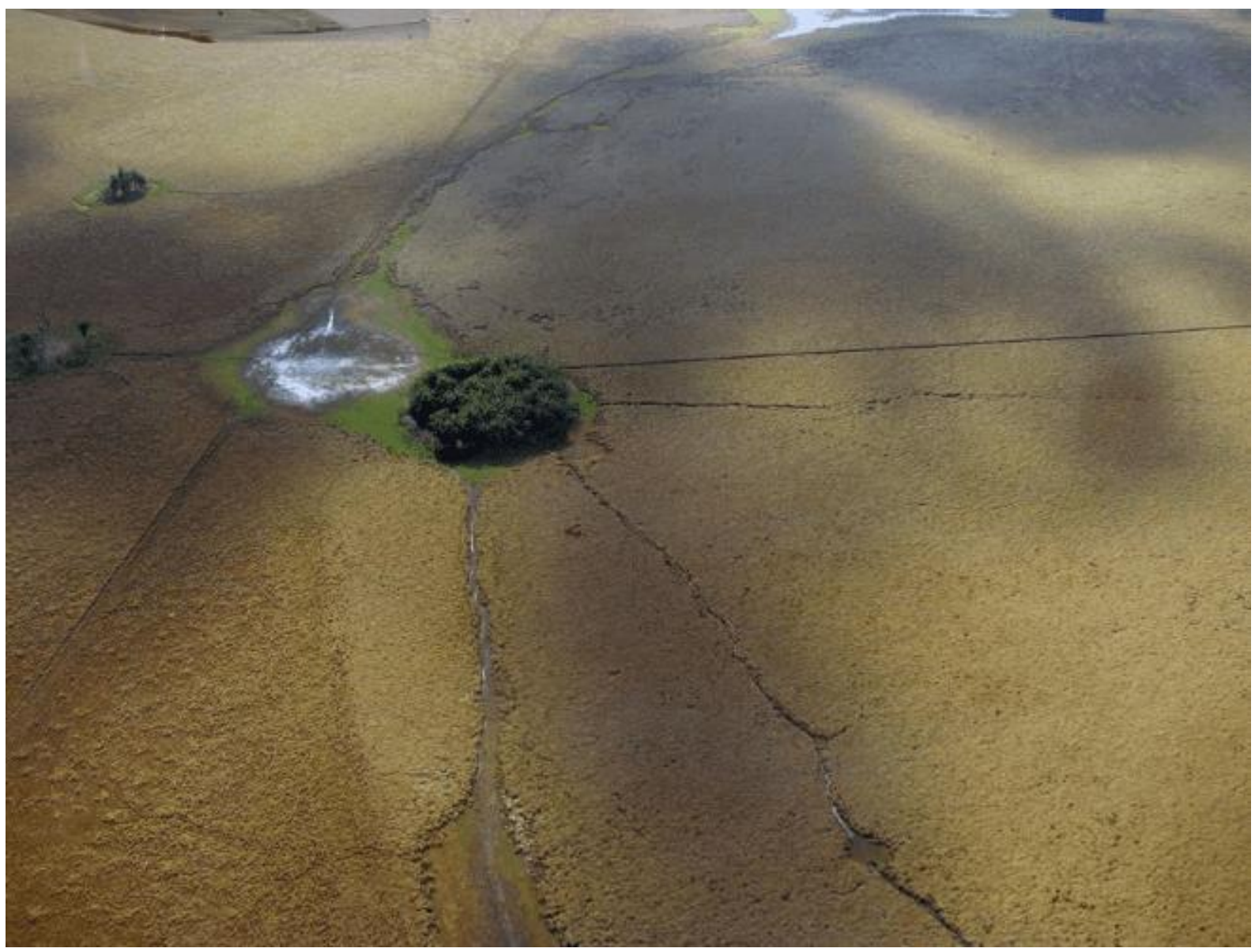

Imagem: Bennett Hennessey.

RC: 13257

Disponível em: https://www.nucleodoconhecimento.com.br/matematica/matematicada-criacao 


\section{DIAGRAMA DA CONSTELAÇÃO DE ÓRION}

Figura 3: Diagrama da Constelação de Órion.

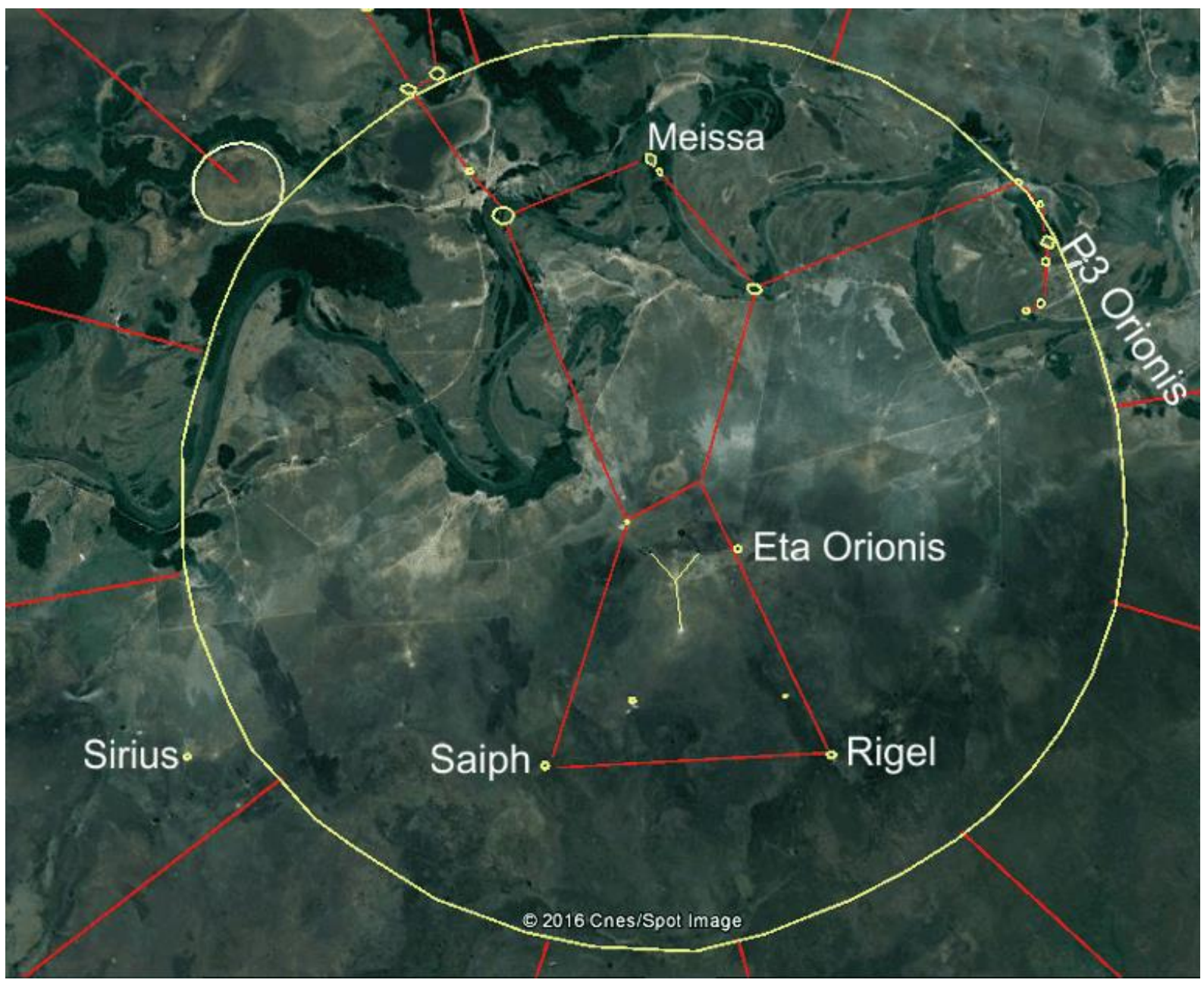

Imagem satelital - Google Earth. Coordenadas: -13.42995, -66.14525

$\mathrm{Na}$ construção do diagrama no solo, ilhas florestas estão distribuídas de uma maneira que nos permite identificar estrelas pertencentes à constelação de Órion como por exemplo: Saiph, Rigel, Tau Orionis, Eta Orionis, além de outras marcações.

RC: 13257

Disponível em: https://www.nucleodoconhecimento.com.br/matematica/matematica- 


\section{REPRESENTAÇÃO DO CINTURÃO DE ÓRION}

Figura 4: Representação do cinturão de Órion.

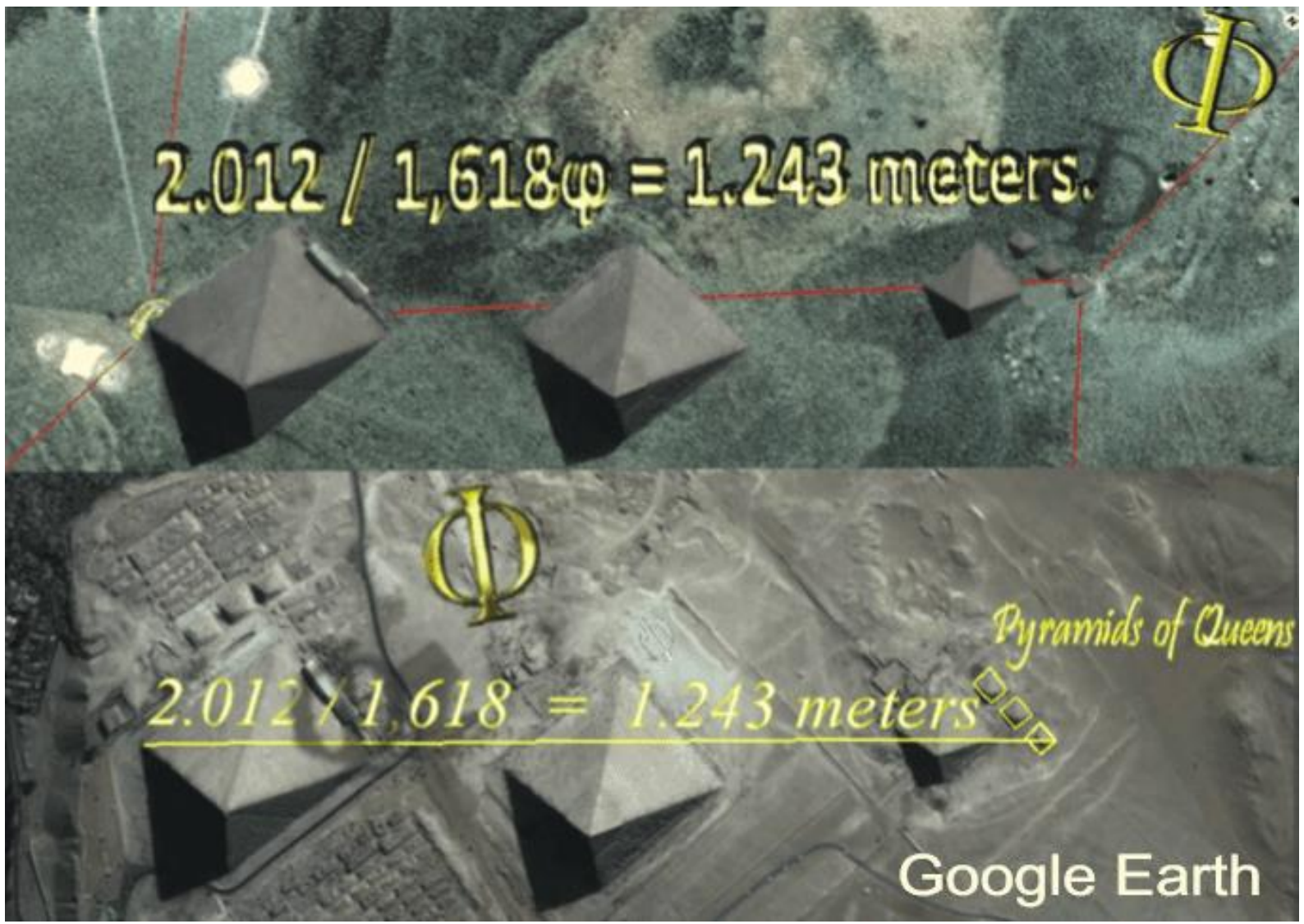

Imagens satelitais - Google Earth

O traço retilíneo feito para representar o cinturão de Órion no diagrama na Amazônia boliviana, traz uma analogia bem interessante, pois ele está na mesma posição e distância em relação às Grandes Pirâmides no Egito, que do mesmo modo, relaciona-se com o cinturão de Órion, ambas as situações, revelam 1.243 metros.

- Ano de $2.012 / 1,618 \Phi$ (proporção áurea $)=1.243$

RC: 13257

Disponível em: https://www.nucleodoconhecimento.com.br/matematica/matematica- 


\section{ALINHAMENTO PRINCIPAL COM 12 SEGMENTAÇÕES}

Figura 5 - Alinhamento principal com 12 segmentações.

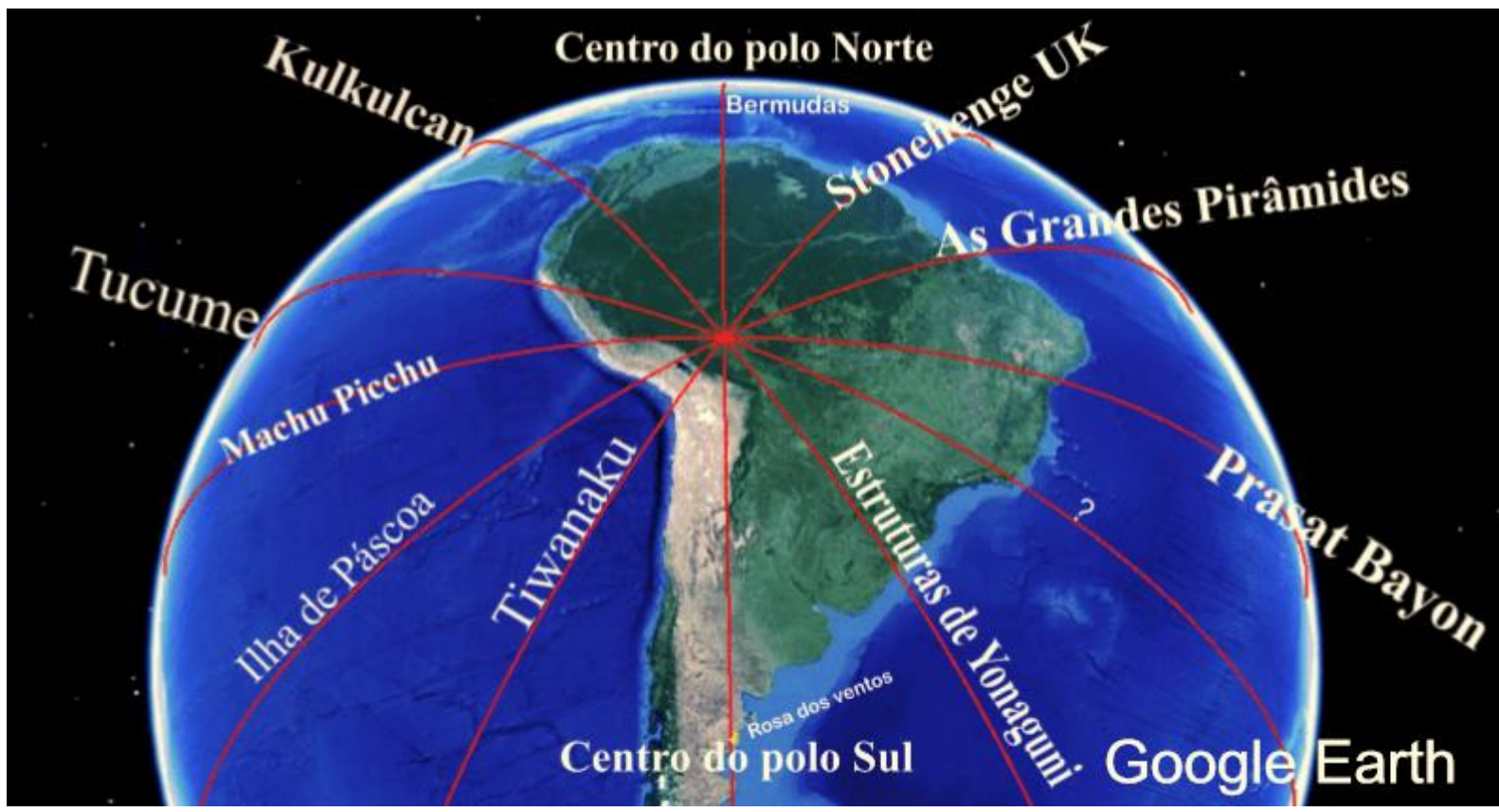

Imagem satelital - Google Earth

Stonehenge,

UK

Tiwanaku,

Peru;

Ilha de Páscoa - As Grandes Pirâmides, Egito;

Machu Piccho, Peru; - Prasat Bayon - Camboja;

Pirâmide de Kulkucan, México - Estruturas de Yonaguni, Japão.

O alinhamento acaba trazendo revelações que nem mesmo os segmentos arqueológicos conhecem, ele expõe 03 medidas que se conectam aos centros dos dois polos, elas são: 5.052 km, 8.516 km e $11.488 \mathrm{~km}$, e que tipo de informações elas trazem? Na verdade, estão servindo de base para a construção de uma regra: todos os grandes monumentos relacionados às civilizações antigas estão se conectando uns com os outros, apresentado variações mínimas em pelo menos uma

RC: 13257

Disponível em: https://www.nucleodoconhecimento.com.br/matematica/matematica- 
dessas 03 mensurações e essa condição serve para todos, não havendo exceção para que alguma estrutura megalítica esteja sozinha sem sua correspondência.

Exemplos dessas conexões e suas variações mínimas entre estruturas relativas as 03 medidas:

- El Mirador - Guatemala, $5.050 \mathrm{~km}$ distante da Ruinas de Huanchacas - Chile.

- Pirâmide de XochiTecatl, México, 5.050 km distante da Isla de la Luna- Peru;

- Stonehenge - UK, 5.052 km distante de Persepolis, Irã;

- Prasat Bayon - Camboja, 8.516 km distante do centro do Polo Norte;

- Prasat Bayon - Camboja, $\mathbf{1 1 . 4 8 8 ~ k m ~ d i s t a n t e ~ d o ~ c e n t r o ~ d o ~ P o l o ~ S u l ; ~}$

- Acrotiri, Santorini - Grécia, $\mathbf{1 1 . 4 8 8 ~ k m ~ d i s t a n t e ~ d e ~ T e l e l e s ~ d e ~ S a n t o ~ N o m b r e ; ~}$ México.

- Acrotiri, Santorini - Grécia, 11.489 km distante de Atalante, México;

- Acrotiri, Santorini - Grécia, 11.484 km distante da Pirâmide do Sol, México;

- Grandes Pirâmides, Egito, 11.465 km distante de El Fuerte de Samaipata Bolívia.

- Centro do alinhamento, Bolívia, 5.052 km distante da Pirâmide de Xochitecatl, México

- Centro do alinhamento, Bolívia, 5.074 km distante de El Tajin, México

- Centro do alinhamento, Bolívia, 8.516 km distante do centro do Polo Sul.

- Centro do alinhamento, Bolívia, $\mathbf{1 1 . 4 8 8}$ km distante do centro do Polo Norte.

- Centro do alinhamento, Bolívia, 11.471 km distante das Pirâmides de Moroe, Sudão.

- Centro do alinhamento, Bolívia, 11.456 km distante do Templo de Ramses II, Egito;

- Centro do alinhamento, Bolívia, 11.448 km distante das Grandes Pirâmides, Egito;

- Centro do alinhamento, Bolívia, $11.448 \mathrm{~km}$ distante de Sun Temple of Niuserre, Egito;

RC: 13257

Disponível em: https://www.nucleodoconhecimento.com.br/matematica/matematica- 
- Centro do alinhamento, Bolívia, 11.448 km distante de Senusret III Pyramid;

- Centro do alinhamento, Bolívia, 11.448 km distante do Temple de Sahure, Egito;

Essas 03 medidas reveladas pelo alinhamento, se tornaram a fonte para que no decorrer dessa pesquisa, eu percebesse que elas estavam diretamente ligadas à precessão dos equinócios da seguinte maneira:

Somando-as o resultado é 25.056 .

A precessão possui um ciclo de 25.920 anos.

- Logo: $25.920-25.056=864$

O Número 864 possui recorrências em várias situações: Um dia $\quad$ possui $\quad \mathbf{8 6 . 4 0 0}$ segundos; O Sol possui um diâmetro $\mathbf{8 6 4 . 0 0 0}$ milhas. (NASA) A precessão dos equinócios possui um ciclo de 25.920 anos Usando a velocidade da luz em uma escala menor:

- $25.920 / 2,99792458=864 \ldots$

Se usarmos apenas os 04 primeiros dígitos da velocidade da luz:

- $25.920 / 29,97=864,864864864 \ldots$

O número 864 corresponde a 12 graus percorridos na precessão. O número 12 é uma das principais correspondências entre os números, ele possui uma significância muito forte, o alinhamento possui 12 segmentações. O sistema usado por uma das primeiras civilizações, os sumérios, era o duodecimal. No modelo padrão as partículas elementares da matéria são 12 em número, os seis quarks, os três elétrons e equivalentes e os três neutrinos. (Bóson de Higgs).

RC: 13257

Disponível em: https://www.nucleodoconhecimento.com.br/matematica/matematica- 
Vejamos como o número 12 está intrinsicamente ligado aos números apresentados: A radiciação é a operação inversa da potenciação. É muito utilizada na obtenção de solução de equações e na simplificação de expressões aritméticas e algébricas. (Mundo Educação)

Sendo

assim,

a

radiciação

de:

4

$=$ $2^{2}$

9

$=$ $3^{2}$

16 $=$ $4^{2}$

Já a radiciação do número 12, não é um número inteiro: $3,4641016^{2}$

\section{MÉTODO}

Os padrões de conexões propostos nesse raciocínio matemático, seguem uma ordem em que os principais números da Matemática, estão relacionados uns com os outros em diferentes escalas.

\section{AS 03 MEDIDAS}

$\begin{array}{lllllll}5.052 & \mathrm{~km}, & 8.516 & \mathrm{~km} & \mathrm{e} & 11.488 & \mathrm{~km} \text {. }\end{array}$

Na radiciação do número 12 (3,4641016...), usaremos: 3.464

- $3.464+5.052($ primeira medida $)=8.516($ segunda medida $)$

Cinturão de Órion: 1.243 metros, usaremos:

A circunferência da Lua: 10.916 km (NASA)

- $10.916 \times 1,243=\mathbf{1 3 . 5 6 8 , 5 8}$

- $13.568-8.516$ (segunda medida) $=5.052$ (primeira medida)

A soma das 03 medidas: 25.056

- $25.056-13.568=11.488$ (terceira medida)

RC: 13257

Disponível em: https://www.nucleodoconhecimento.com.br/matematica/matematica- 
- $13.568+3.464=17.032 / 2=8.516$ (segunda medida)

A circunferência da Lua e o cinturão de Órion evidenciam: 13.568 que se conecta perfeitamente com as 03 medidas.

\section{1,618 Ф PROPORÇÃO ÁUREA}

Existe um número na natureza que, desde a Antiguidade, desperta a curiosidade e o fascínio de matemáticos e estudiosos: o número phi $(\Phi=1,618)$ Também chamado número de ouro, ele está por traz de importantes obras da arquitetura clássica, em pinturas e esculturas renascentistas, na natureza, incluindo no corpo humano. Um número mágico, que organiza o universo em uma mesma proporção, a divina proporção. (Revista Pre-Univesp)

\section{UM ANO-LUZ: 9.460.800.000 KM}

É a distância que a luz atravessa no vácuo em um ano. (VITOR NUNES 2017) 9.460.800.000 km. (Nove trilhões, quatrocentos e sessenta bilhões e oitocentos milhões de quilômetros)

Usaremos: (94.608)

- $94.608 / 12=7.884$

1,618 Ф proporção áurea.

- 7.884 x 1,618 Ф (proporção áurea $)=12.756,36$

Diâmetro da Terra é de 12.756 km. (NASA)

De acordo com a pesquisa do arquiteto Miguel Pérez-Sánchez o ângulo de inclinação da Grande Pirâmide é de: 51,84 (PÉREZ SANCHES, MIGUEL - 2.012)

O número 5.184, também está diretamente ligado à precessão dos equinócios.

$\mathrm{RC}: 13257$

Disponível em: https://www.nucleodoconhecimento.com.br/matematica/matematica- 
25.920 anos $\times 2=51.840$

- 94.608 (ano-luz) / $12=7.884$

- $\quad 7.884+51.840=59.724$ essa sequência numérica corresponde justamente à massa da Terra que é: $5,9724 \times\left(10^{24} \mathrm{~kg}\right)$. (NASA)

A precessão dos equinócios: 25.920 anos.

Durante 365 dias, a luz percorreu $9.460 .800 .000 \mathrm{~km}$.

- 25.920 anos x 365 dias $=9.460 .800$, mesma sequência numérica relativa ao ano-luz.

\section{A MEIA VIDA DO CARBONO 14}

No ano de 1947, o químico Willard Libby fez uma descoberta que mudaria a história da Arqueologia, a partir de seus estudos seria possível decifrar a idade de fósseis antigos.

As pesquisas de Libby revelaram que a quantidade de carbono 14 dos tecidos orgânicos mortos diminui a um ritmo constante com o passar do tempo. Assim, a medição dos valores do isótopo radioativo em um objeto fóssil nos dá pistas muito exatas dos anos decorridos desde sua morte.

A partir da morte de um ser vivo, a quantidade de C-14 existente no tecido orgânico se dividirá pela metade a cada 5.730 anos, é o que se chama de meia vida do carbono. (LÍRIA ALVES. Brasil escola 2015).

O ângulo da Pirâmide de Quéops: $51,84^{\circ}$ e suas diferentes escalas, aparecem constantemente nos cálculos.

- $\quad 5.730+5.184=10.914$, esse resultado é uma aproximação da circunferência da lua com $10.916 \mathrm{~km}$.

$\mathrm{RC}: 13257$

Disponível em: https://www.nucleodoconhecimento.com.br/matematica/matematica- 
Se 5.730 anos é também um valor aproximado, 5.732 anos poderia ser uma referência mais correta para esse decaimento.

- $\quad 5.732+5.184=10.916 \mathrm{~km}$

Ao que parece, os números relativos à precessão dos equinócios, causam algumas reflexões, pois estão possivelmente, corrigindo alguns resultados que se relacionam com várias situações que compuseram a estrutura de nosso sistema solar, todos eles também diretamente ligados com as dimensões da Terra, da Lua e do Sol e com as 03 medidas.

\section{NÚMEROS PERFEITOS}

Em Matemática, um número perfeito é um número inteiro para o qual a soma de todos os seus divisores positivos próprios (excluindo ele mesmo) é igual ao próprio número. (CARLOS MACORATTI, JOSÉ - 2017)

Os quatro primeiros números perfeitos são: 6, 28, 496 e 8.128 . A soma dos divisores excluindo 0 próprio número: $6+\begin{array}{llll}1 & + & 2 & +\end{array}$ $28=1+2+4+74$ $496=1+2+4+8+16+31+62+124+248$ $8128=1+2+4+8+16+32+64+127+254+508+1016+2032+4064$

\section{SOMANDO-OS}

- $6+28+496+8.128=8.658$

O ângulo da Grande Pirâmide numa escala maior: 5.184.

- $8.658-5.184=3.474$

RC: 13257

Disponível em: https://www.nucleodoconhecimento.com.br/matematica/matematica- 
Diâmetro da Lua: 3.474 km. (NASA)

\section{O RAIO TERRESTRE}

O raio terrestre é a distância entre o centro da Terra e sua superfície. Devido ao fato de que a Terra não é uma esfera perfeita, não há um único valor que sirva como seu raio natural. Ao invés disso, sendo quase esférica, vários valores, desde o raio polar (de $6.357 \mathrm{~km})$ ao raio equatorial $(6.378 \mathrm{~km})$ são utilizados, de acordo com a necessidade, e modelos da Terra assumindo esta como uma esfera geram um raio médio de $6.371 \mathrm{~km}$. (Wikipédia)

\section{SIMPSONS E A MATEMÁTICA}

Figura 6 - Simpsons e a Matemática

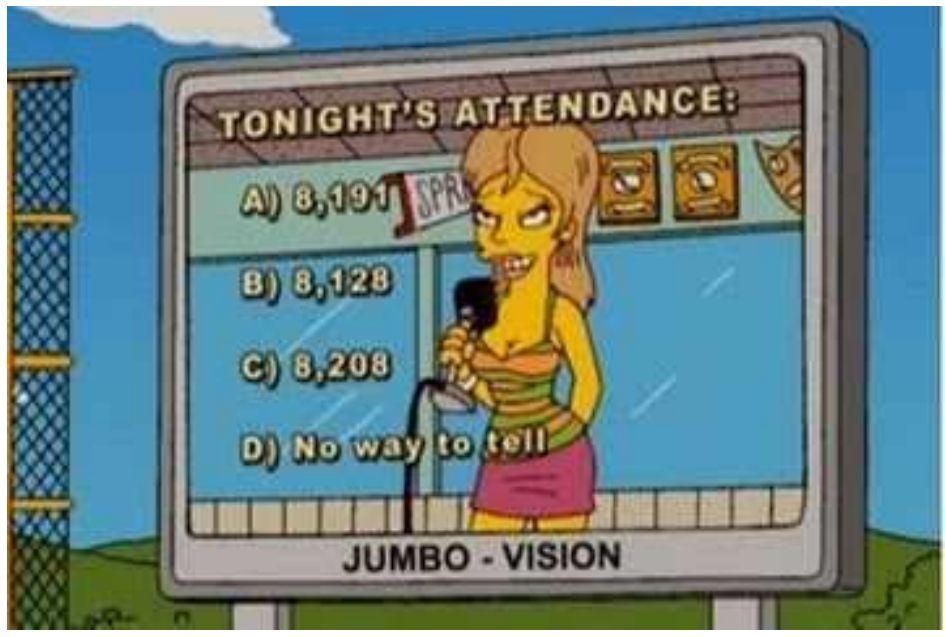

Imagem de divulgação da 20th Century Fox.

Em um episódio de: Os Simpsons, alguns números desconhecidos do público em geral são apresentados em um placar numa questão de múltipla escolha, eles são: 8.128, 8.208 e 8.191, na realidade, eles aparecem por que são números muito especiais para quem está habituado com a Matemática, pois 8.128 é um "número

RC: 13257

Disponível em: https://www.nucleodoconhecimento.com.br/matematica/matematica- 
perfeito", 8.208 é um "número narcisístico" e 8.191 é um "número primo de Mersenne". (Manuel Ansede - 2015).

Há uma explicação lógica para Os Simpsons apresentarem de maneira subliminar números tão sofisticados no decorrer de seus episódios, isso também torna a animação mais intrigante pois, na verdade os roteiristas da série: J. Stewart Burns, Al Jean e Ken Keeler, são matemáticos formados pela Universidade de Harvard (EUA), e David X. Cohen e Jeff Westbrook, ambos físicos, também são formados pela mesma universidade, esta é a justificativa para esses e outros números serem apresentados de maneira tão recorrente na animação.

- O número 8.128, o quarto dos chamados números perfeitos, igual à soma de seus divisores excluindo ele mesmo:

$8128=1+2+4+8+16+32+64+127+254+508+1016+2032+4064$

- O Número 8191 é igual a 213 - 1 e, portanto, é o quinto dos chamados primos de Mersenne.

- O número 8.208 é um dos números narcisistas, aqueles iguais à soma de cada um de seus dígitos elevados a $n$

Exemplo: $84+24+04+84=4096+16+0+4096=8.208$. Somando esses 03 números:

- $8.128+8.191+8.208=24.527(245,27)$

- 245,27 x 25,920 anos $=6.357,39$ (o raio polar da Terra $6.357 \mathrm{~km}$ )

Ângulo da Grande Pirâmide: 51,84ํㅜ (5.184) \& $(2,4527)$

- $\quad 5.184 \times 2,4527=12.714,79$

RC: 13257

Disponível em: https://www.nucleodoconhecimento.com.br/matematica/matematica- 
Diâmetro

polar

da

Terra:

12.714

$\mathrm{km}$.

(NASA)

Diâmetro Equatorial da Terra: 12.756 km. $(1,2756)$

- O número perfeito $8.128 / 1,2756=6.371,90$ (raio médio da Terra: $6.371 \mathrm{~km}$ ).

As somas que nos levam ao $4^{\circ}$ número perfeito 8.128 , também expõe um outro com uma relevância muito forte dentro desses cálculos, ele é o resultado da $12^{\mathrm{a}}$ soma $=$ 4.064.

$1+2+4+8+16+32+64+127+254+508+1016+2032+(\underline{4064})$.

\section{DE DEZEMBRO (25/12)}

A data do nascimento de Cristo é comemorada mundialmente no dia: 25/12, contudo, ela traz consigo algumas outras observações, onde alguns estudiosos como: o escritor e biólogo evolutivo Richard Dawkins, o jornalista Christopher Hitchens e o filósofo francês Michel Onfray relatam a existência de que outros messias solares possuem as mesmas coincidências com relação ao dia de seu nascimento. (Vida em Órbita 2011)

- Horus, deus egípcio do Sol nasceu no dia 25 de dezembro.

- Dionísio, deus grego nasceu no dia 25 de dezembro.

- Mitra, deus persa do Sol, nasceu de uma virgem no dia 25 de dezembro.

Independente de crenças, costumes, essa data foi usada como uma alegoria para simbolizar o nascimento de distintas entidades solares em épocas e lugares distintos, mesclando com isso, tradições diferentes no decorrer de nossa história, envolvendo-nos de uma maneira ou de outra a esse período específico. Como todos os principais números da Matemática estão se conectando as dimensões de nossos principais astros, com a precessão dos equinócios e com as 03 medidas, essa data por sua importância religiosa, deverá possuir conexões

RC: 13257

Disponível em: https://www.nucleodoconhecimento.com.br/matematica/matematica- 
pertinentes

a

esses

padrões

matemáticos.

$25 / 12(2.512)$

- 2.512 x 1,618 $\phi$ (proporção áurea $)=4.064,41$

A $1^{\circ}$ medida e o cinturão de Órion:

- $5.052 \backslash 1,243=4.064,36$

Raio equatorial da Terra: $6.378 \mathrm{~km}$

- 4.064 x 6,378 = 25.920,19 (a precessão dos equinócios: 25.920 anos)

Ângulo da Pirâmide de Quéops: 51,84ํำ

- $\quad 4.064$ / 518,4 = 7,83... (Ressonância Schumann: 7,83 hz)

Raio polar da Terra: $6.371 \mathrm{~km}$

- $\quad 40.640 / 6,371=6.378,90$ (raio equatorial da Terra: 6.378 km)

\section{CARGA ELÉCTRICA ELEMENTAR}

A carga eléctrica elementar (e) corresponde, por definição, a menor carga (indivisível) que pode ser detida por uma partícula, sendo por isso utilizada como unidade de medida de carga eléctrica no sistema de unidades atómicas. Millikan recebeu o Prémio Nobel de Física de 1923, pelos trabalhos que desenvolveu sobre cargas elétricas elementares e o efeito fotoelétrico, onde conseguiu determinar a carga elementar no valor de: $E=1,602$ x 10-19. (Fciências 2011)

- $E=1,602 \times 1,618 \Phi$ (proporção áurea) = 2,5920 $\ldots$ (precessão dos equinócios 25.920 anos).

RC: 13257

Disponível em: https://www.nucleodoconhecimento.com.br/matematica/matematica- 


\section{LEI DA GRAVITAÇÃO UNIVERSAL (ISAAC NEWTON)}

Ao estudar o movimento da Lua, Newton concluiu que a força que faz com que ela esteja constantemente em órbita é do mesmo tipo que a força que a Terra exerce sobre um corpo em suas proximidades. A partir daí criou a Lei da Gravitação Universal.

"Dois corpos atraem-se com força proporcional às suas massas e inversamente proporcional ao quadrado da distância que separa seus centros de gravidade." (Só Física.2017).

$\mathrm{G}=$ Constante de gravitação universal $\mathrm{G}=6,67 \times 10-11 \quad \mathrm{~N} \cdot \mathrm{m}$ 2/kg2. Meio ciclo da precessão dos equinócios: 12.960 anos

- $25.920 / 2=12.960$

- $129,60 \times 6,67=864,432$

- $\mathrm{G}=6,67-1,618 \Phi$ (proporção áurea $)=5,052\left(1^{\text {a }}\right.$ medida: $\left.5.052 \mathrm{~km}\right)$.

\section{RESSONÂNCIA SCHUMANN DE 7,83 HZ}

A Ressonância Schumann é um conjunto de picos no espectro na ELF (banda de frequências extremamente baixas) do espectro do campo eletromagnético terrestre, formado pela superfície da Terra e pelas camadas inferiores da ionosfera, sua frequência e de $7,83 \mathrm{hz}$.

O físico alemão W.O. Schumann constatou, em 1952, que a Terra é cercada por um campo eletromagnético poderoso, que se forma entre o solo e a parte inferior da ionosfera - que fica cerca de 100 km acima de nós. Esse campo possui uma ressonância (daí chamar-se ressonância Schumann), mais ou menos constante, da ordem de 7,83 pulsações por segundo. Funciona como uma espécie de marcapasso, responsável pelo equilíbrio a biosfera, condição comum de todas as formas

RC: 13257

Disponível em: https://www.nucleodoconhecimento.com.br/matematica/matematica- 
de

vida.

(Patricya

Travassos

Gnt-2012).

$\underline{7,83 \mathrm{hz}}$

- $\quad$ 7,83 hz - 6,67 (gravitação universal) =1,16

- 1,16 x 2,160 (uma era na precessão 2.160 anos) = 2,5056 (soma das 03 medidas: 25.056)

- $\quad 1,16$ x 12 = 13,92 (diâmetro do Sol: 1.392 .000 km) (NASA)

\section{CIRCUNFERÊNCIA DO SOL}

Em alguns sites oferecidos pelos mecanismos de buscas como por exemplo o Google, há vários resultados pertinentes à circunferência do Sol quando pesquisamos, contudo, um deles, apresentou-se de maneira muito satisfatória com as conexões nesses padrões matemáticos apresentados, ele é: $\underline{4.346} .000 \mathrm{~km}$. (BuzzFeed-2015), Esse resultado sobre a circunferência do Sol, possui uma desenvoltura muito peculiar, uma vez que, ele se conecta com resultados pertinentes à precessão dos equinócios, velocidade do som, Ressonância Schumann, as 03 medidas e com o Bóson de Higgs. Essas situações colaboraram bastante para que eu pudesse de fato, escolhê-lo. Circunferência do Sol: 4.346 .000 km $(43,46)$

- 43,46 x 7,83 hz (Ressonância Schumann) = 340,29 (a velocidade do Som: $340,29 \mathrm{~m} / \mathrm{s})$

Esse resultado é muito interessante, a dimensão do nosso astro principal, associado a uma frequência, resulta justamente na velocidade de uma onda.

- $\quad 4.346 \times 12=52.152 / 2,012$ (ano) $=25.920$ anos
A Circunferência
do
Sol:
4.346 .000
$\mathrm{km}$
O diâmetro do Sol: 1.932 .000 km

$\mathrm{RC}: 13257$

Disponível em: https://www.nucleodoconhecimento.com.br/matematica/matematica- 
- $4.346 / 1.392,00=3,122 \ldots$

- 4.346 x 3,122 = 13.568,21 (novamente o mesmo número que se conecta com as 03 medidas)

- $13.568-8.516$ (segunda medida) $=5.052$ (primeira medida)

- A soma das 03 medidas: 25.056

- $25.056-13.568=11.488$ (terceira medida)

- 4.346 x 2,512 (25 de dezembro) = 10.917 (circunferência da Lua: 10.916 km)

\section{O NÚMERO DE SRINIVASA RAMANUJAM: 1.729}

Srinivasa Ramanujam foi um matemático indiano, onde fez contribuições substanciais para análise matemática, teoria dos números, séries infinitas e frações continuadas, incluindo soluções para problemas matemáticos considerados insolúveis.

Um dos números mais conhecidos desse matemático e o menor número natural representado, de duas formas diferentes, pela soma de dois cubos: $1.729=103+93$ $=13+123$. (BBC News.2013).

51,84º ângulo da pirâmide de Quéops e a velocidade da luz 299.792,458

- $5.184 / 2,99792458=\underline{1.729}, 19$

- $\quad \pi \times 1,618 \Phi($ proporção áurea) $\times 340,29$ (velocidade do som) = 1.729,72

- 11.488 (terceira medida) - 8.516 (segunda medida) $=2.972$

- $\quad 2.972-1.729=1.243$ metros (cinturão de Órion)

- $1.729 \times 5,184=8.963$

- $8.963-6.371$ (raio polar da Terra) = 2.592 (precessão dos equinócios: 25.920 anos)

$\mathrm{RC}: 13257$

Disponível em: https://www.nucleodoconhecimento.com.br/matematica/matematica- 


\section{NÚMERO DE EULER}

Na matemática, o número de Euler, denominado em homenagem ao matemático suíço Leonhard Euler, é a base dos logaritmos naturais. As variantes do nome do número incluem: número de Napier, número de Neper, constante de Néper, número neperiano, constante matemática, número exponencial etc. A primeira referência à constante foi publicada em 1618 na tabela de um apêndice de um trabalho sobre logaritmos de John Napie. (Wikipédia 2016).

O ano da primeira publicação é bem interessante, 1.618, numa escala menor é justamente a representação da proporção áurea.

O número dourado: $1,618 \Phi$

Número de Euler é de aproximadamente: 2,71828...

- $2,71828^{\wedge 1} 1,618 \Phi=5,042 \ldots$ (potenciação)

Numa escala maior $5.042=1 \times 2 \times 3 \times 4 \times 5 \times 6 \times 7$

- $5.042+12=5.052$ (1ํㅡㄹ medida)

- 2,71828 (Número de Euler) x $\underline{635,7}$ (6.357 km raio polar da Terra) $=1.728,01$

- $1.728 / 2=864$

- $1.728=123$

- 2,71828 (Número de Euler) + 1,602 (carga eléctrica elementar) +8,64 = 12,960

(12.960 anos corresponde à metade do ciclo da precessão dos equinócios).

Lei da gravitação universal (Isaac Newton): $\mathrm{G}=\underline{6,67} \times 10-11$ N.m 2/kg2.

- $2,71828^{\wedge} 6,67=788,39$ (potenciação)

- 7883,9 x 1,618 $\Phi=12.756,15$ (diâmetro equatorial da Terra: 12.756 km)

$\mathrm{RC}: 13257$

Disponível em: https://www.nucleodoconhecimento.com.br/matematica/matematica- 


\section{O BÓSON DE HIGGS}

O modelo padrão postula que a matéria é composta por 12 partículas: seis tipos de quarks, e seis tipos de léptons. Segundo o modelo, quarks e léptons são indivisíveis.

A tabela de partículas contém 12 partículas elementares (férmions) classificadas em três gerações da matéria, matéria que nos rodeia faz parte da primeira geração. As 12 partículas elementares da matéria são, os seis quarks (Up, Charm, Top, Down, Strange, Bottom) os trêselétrons (elétron, múon, tau) e os três neutrinos (elétron, múon, tau). Quatro dessas partículas elementares são suficientes, em princípio, para construir o mundo que nos rodeia. (ASTRONOO - 2013).

No espaço vazio, o campo de Higgs adquire um valor diferente de zero, que permeia a cada lugar no universo todo o tempo. Este valor da expectativa do vácuo (VEV) do campo de Higgs é constante e igual a $246 \mathrm{GeV}$. (RAFAEL COIMBRA - 2017) Usando tecnologias diferentes, os laboratórios Atlas e CMS encontraram que a inalcançável partícula tem uma massa de 125,09 giga elétron-volt (GeV), com uma margem de erro de 0,24 GeV para mais ou para menos. (Exame- 2015).

A seguir iremos apresentar alguns exemplos pertinentes aos resultados divulgados pelo Cern em (Giga electron volts Gev). Como foi dito no o início, tudo se conecta em diferentes escalas:

- $12.509 \mathrm{Gev}+246 \mathrm{Gev}=12.755$ (diâmetro equatorial da Terra: $12.756 \mathrm{~km}$ )

- 12.755 / $246 \mathrm{Gev}=51,84 \ldots$ (ângulo da Pirâmide de Quéops: 51,84º).

$246 \mathrm{GeV}$

- 24,6 Gev / $\pi$ = 7,83... (Ressonância Schumann: 7,83 hz)

- 1.243 (cinturão de Órion) / $246 \mathrm{Gev}=5,052 \ldots$ (1 ${ }^{\text {a }}$ medida: 5.052 km)

- $\mathrm{G}=6,67$ (gravitação universal) $-2,46 \mathrm{Gev}=4,21$

- $4,21 \times 12=50,52$ (primeira medida: 5.052)

$\mathrm{RC}: 13257$

Disponível em: https://www.nucleodoconhecimento.com.br/matematica/matematica- 
- 5,052 - 2,46 Gev = 2,592 (precessão dos equinócios: 25.920)

Em astronomia, o raio solar é uma unidade de comprimento usada para expressar o tamanho das estrelas.

Seu valor é de: $R \odot=6,960 \times 108 \mathrm{~m}=0,004652$. A Soma das 03 medidas: 25.056

$12 \times 3=36(3,6)$

- $25.056 / 3,6=6.960$

$125,09 \mathrm{Gev}$

- 12.509 Gev / 3,6 = 3.474,72 (diâmetro da Lua: 3.474 km).

Circunferência do Sol: 4.346 .000 km (4.346)

- $4.346 / 1,2509 \mathrm{Gev}=3.474,29$ (novamente o diâmetro da Lua).

\section{A TERRA, A LUA E O SOL}

Diâmetro

do

Sol:

1.392 .000

$\mathrm{km}$.

Circunferência da Terra: 40.075 km. (ASTRONOO)

- $\quad 1.392 .000 / 40.075=34,73 \ldots$ (diâmetro da Lua: 3.474 km)

\section{CONCLUSÃO}

Uma região inóspita da Amazônia boliviana localizada na província de Beni revela um alinhamento entre as principais estruturas megalíticas e sua simetria não consegue ser replicada em nenhum outro lugar, ele conecta tudo no planeta à constelação de Órion, numa espécie de diagrama onde as referências estelares são representadas por ilhas florestas, estudos recentes, realizados principalmente pelo

RC: 13257

Disponível em: https://www.nucleodoconhecimento.com.br/matematica/matematica- 
engenheiro boliviano David Antelo Justiliano, (La Conspiración Atlante: Yesusa'Iri 2008) onde duplicando as coincidências encontradas nos diálogos de Platão sobre Atlântida, acaba convergindo para uma vasta área localizada em Beni, onde sugere que uma civilização hidráulica tenha prosperado em um passado longínquo, sendo ela capaz de dominar as águas por toda essa região e possivelmente seu desaparecimento se deu por meio de um cataclismo, além disso, a arquitetura empregada nesse alinhamento, nos traz outras analogias que nos remetem às encontradas nas estruturas das Grandes Pirâmides no Egito, nesse caso, o traço retilíneo feito para representar o cinturão de Órion com seus 1.243 metros sugere um mesmo tipo de conhecimento empregado. A Matemática apresentada pelo alinhamento revela que essa localização deva ter sido em um determinado período, o centro de uma civilização muito importante, pois o local exposto pelo diagrama, no caso, o Centro do alinhamento, Bolívia, é onde há o maior número de conexões entre as 03 medidas com outras estruturas, por regra, todas devem possuir suas correspondências e nesse entendimento, esse local corrobora para a existência de um sítio arqueológico ainda não identificado abaixo do solo, além disso, outras situações onde as dimensões da Terra, da Lua e do Sol, por estarem intrínsecas nos principais números da Matemática, desqualificam teorias em que o sistema Solar tenha se formado de maneira aleatória, sendo uma obra do acaso, os principais números da Matemática apresentados aqui, nos dizem que o universo desde seu início, conspirou deliberadamente para que nós existíssemos e as civilizações de outrora demonstram o quão eram avançadas em seus conhecimentos, sabiam que essa resposta estaria codificada nesse evento astronômico conhecido como: a precessão dos equinócios ocorrido em 2012 e elaboraram de maneira surpreendente monumentos alinhados a esse período, capazes de suportarem a ação do tempo, com a finalidade de alertarem as gerações futuras a respeito da grandiosidade desse evento astronômico, para que de fato, venhamos a entender qual o verdadeiro motivo de nossa existência, nessa singularidade que até então, é a única que possuímos a certeza de abrigar a vida, conhecida como Terra.

RC: 13257

Disponível em: https://www.nucleodoconhecimento.com.br/matematica/matematica- 


\section{REFERÊNCIAS}

ALVES, LíRIA. Brasil escola. Carbono 14. Encontrado em: http://brasilescola.uol.com.br/quimica/carbono-14.htm (setembro de 2017) ANSEDE, MANUEL. Os 10 melhores momentos matemáticos de 'Os Simpsons'. Encontrado

em: https://brasil.elpais.com/brasil/2015/04/30/ciencia/1430420317_959498.html (Acesso em: junho de

ANTELO JUSTILIANO, DAVID. La Conspiration Atlante. Encontrado em: http://atlantisforschung.de/index.php?title=David_Antelo_Justiniano (Acesso em: outubro de 2015)

ASTRONOO. Circunferência da Terra. Encontrado em: http://www.astronoo.com/pt/artigos/astronomia-tempo-civilizacoes.html (Acesso em: agosto de

ASTRONOO. 12 partículas da matéria. Encontrado em: http://www.astronoo.com/pt/artigos/particulas-subatomicas.html (Acesso em: agosto de

BBC News. Número de Srinivasa Ramanujan. Encontrado em: http://www.bbc.com/news/magazine-24459279 (Acessado em: maio de 2016) CARLOS MACORATTI, JOSÉ. Números perfeitos. Encontrado em: http://www.macoratti.net/13/07/net_nuperf.htm (Acesso em: setembro de 2017) COIMBRA, RAFAEL. Uma breve abordagem da Teoria das partículas elementares. Encontrado: http://socientifica.com.br/2017/06/uma-breve-abordagem-da-teoria-dasparticulas-elementares/ (Acesso em novembro de 2017) Exame. Bóson de Higgs. Encontrado em: https://exame.abril.com.br/ciencia/laboratorios-do-cern-encontram-medidas-precisasdo-boson-de-higgs/ (Acesso em: setembro de 2017) Fciências. MILLIKAN, ROBERT (1868 - 1953). Carga elétrica elementar. Encontrado em:

http://www.fciencias.com/2011/11/15/experiencias-de-millikan/ (Acesso em: agosto

RC: 13257

Disponível em: https://www.nucleodoconhecimento.com.br/matematica/matematica- 
de

2017)

GADALLA, MOUSTAFA. A Cosmologia Egípcia: O Universo Animado. Precessão dos Equinócios - 2017. Capítulo 15 - Pág. 117 - 119. Hypescience. Calendário maia. Encontrado em: https://hypescience.com/profecia-maia-calendario-2012/ (Acesso em: outubro de 2017)

Mundo Educação. Radiciação. Encontrado em: http://mundoeducacao.bol.uol.com.br/matematica/radiciacao.htm (Acesso em: agosto de 2017) MUNIZ, GUSTAVO: Órion. A conexão entre o céu e a Terra. https://www.livrariaanunaki.com.br/orion-a-conexao-entre-o-ceu-e-a-terra NASA. Circunferência da Lua. Solar System Exoploretion. Encontrado em: http://certificate.ulo.ucl.ac.uk/modules/year_one/NASA_SSE/earth_moons_facts.html (Acesso em: junho de NASA. Diâmetro da Lua. Encontrado em: https://www.nasa.gov/mission_pages/msl/multimedia/pia17351.html\#.WjqS8TfJ2M8 (Acesso em: agosto de 2017) NASA. Diâmetros da Terra. 10 interesting things about Earth. Encontrado em: https://climate.nasa.gov/news/2469/10-interesting-things-about-earth/ (Acesso em: agosto

NASA. Diâmetro do Sol, Encontrado em: https://spaceplace.nasa.gov/suncompare/sp/ (Acesso em:

outubro de 2017) NASA Massa da Terra. Encontrado em: https://nssdc.gsfc.nasa.gov/planetary/factsheet/sunfact.html (Acesso em: junho de 2016)

NUNES, VITOR. Matemática.pt. Ano-luz. Encontrado em: https://www.matematica.pt/faq/ano-luz.php (Acesso em: setembro de 2017) PÉREZ SANCHES, MIGUEL: A Grande Pirâmide: A Chave Secreta do Passado (Ângulo da Grande Pirâmide). Encontrado em: http://www.soloespolitica.com/foro/viewtopic.php?t=31455\&p=1004445 (Acesso em:

$\mathrm{RC}: 13257$

Disponível em: https://www.nucleodoconhecimento.com.br/matematica/matematica- 
agosto

de

2017)

Revista Pre-Univesp. Equação Áurea. Encontrado em: http://pre.univesp.br/onumero-de-ouro-e-a-divina-proporcao\#.WjqgRjfJ2M8 (Acesso em: outubro de 2017) RUTHERFORD, FIONA. BuzzFeed News Reporter. Circunferência do Sol. Encontrado em: https://www.buzzfeed.com/fionarutherford/19-fatos-que-mudaraoseu-jeito-de-pensar-a-vida?utm_term=.rodDIExW\#.vmK3b6rE (Acesso em: agosto de

Só Física. Constante de gravitação universal. Encontrado em: http://www.sofisica.com.br/conteudos/Mecanica/GravitacaoUniversal/gu.php (Acesso em: setembro

de

TRAVASSOS. PATRICYA (GNT). Ressonância-Schumann. Encontrada em: http://gnt.globo.com/bem-estar/materias/voce-ja-ouviu-falar-em-ressonancia-

schumann.htm (Acesso maio de 2015)

Vida em Órbita, Nascimento de Cristo. Encontrado em: http://vidaemorbita.blogspot.com.br/2011/07/voce-sabe-quantos-deuses-temhistoria.html (Acesso em: setembro de 2017) Wikipédia. 2012 Fenômeno Encontrado em: https://pt.wikipedia.org/wiki/Fenômeno_2012 (Acesso em: outubro de 2017) Wikipédia. Número de Euler. Encontrado em: https://pt.wikipedia.org/wiki/N\%C3\%BAmero_de_Euler (Acesso em: agosto de 2017) Wikipédia. Raio solar. Encontrado em: https://pt.wikipedia.org/wiki/Raio_solar (maio de

Wikipédia. Raio Terrestre. Encontrado em: https://pt.wikipedia.org/wiki/Raio_terrestre (Acesso em: outubro de 2017) Wikipédia. 2012 (FILME) encontrado em: https://pt.wikipedia.org/wiki/2012_(filme) (Acesso em: outubro de 2017) Todas as imagens satelitais são de propriedade do Google Earth.

$\mathrm{RC}: 13257$

Disponível em: https://www.nucleodoconhecimento.com.br/matematica/matematica- 